\title{
POEMAS DE CLAUDIO DANIEL
}

(tradução de Jesús J. Barquet*)

\section{SOBRE O AUTOR:}

Claudio Daniel, pseudônimo de Claudio Alexandre de Barros Teixeira, nasceu em 1962, em São Paulo. Poeta e tradutor, publicou os livros de poesia Sutra (São Paulo: João Scortecci, 1992), Yumê (São Paulo: Ciência do Acidente, 1999) e, em parceria com Luiz Roberto Guedes, Geometria da água $\&$ outros poemas (São Paulo: Memorial da América Latina, 2000), com traduções do poeta cubano José Kozer. O livro $A$ sombra do leopardo permanece inédito.

\section{SOBRE O TRADUTOR:}

Jesús J. Barquet nasceu em 1953, em Havana, Cuba. Como poeta publicou, entre outros, os livros Sin decir el Mar (Madrid: Playor, 1981), Un no rompido Sueño (Santo Domingo: Punto Creativo, 1994), El Libro del Desterrado (Chihuahua: Azar, 1994) e Naufragios/Shipwrecks (Las Cruces: Puerto del Sol, 2000). Como ensaísta, publicou Consagración de La Habana (Coral Gables: University of Miami) e Escrituras Poéticas de una Nación (La Habana: UNEAC, 1999).

\footnotetext{
(*) Professor do Departamento de Letras Modernas da FFLCH-USP.
} 


\section{CANÇÃO DA ÁRVORE DE MIL FOLHAS*}

o que exprime

essa esgrima silenciosa

esse pugilato de sombras?

simulacro de suave tigre-de-água e leo dragão-de-vento

flama de branca acácia e de salmão pequeno

que combate no limiar entre a pele e a alma.

o que irradia

esse lento balé de plumas

esse desfile de facas e leques?

dança que traduz em seus passos, hábeis como a pantera

a canção da árvore de mil folhas

que não sabe da língua

mas do coração

[* Nota do autor: Árvore de mil folhas e pugilato de sombras são expressões que designam o tuey shou, série de exercícios para dois praticantes que integra a arte marcial chinesa do tai chi chuan.] (1991, in Sutra)

\section{CANCIÓN DEL ÁRBOL DE MIL HOJAS*}

¿qué expresa

esta esgrima silenciosa

este pugilato de sombras?

simulacro de suave tigre-de-agua y leonín dragón-de-viento

llama de blanca acacia y salmonete

que combate en el umbral entre la piel y el alma.

¿qué irradia

este lento ballet de plumas

este desfile de abanico y cuchillos?

danza que en sus pasos traduce, hábiles como la pantera,

la canción del árbol de mil hojas

que no sabe de lengua

sino de corazón

[* Nota del autor: Árbol de mil hojas y pugilato de sombras son expresiones que se refieren al tuey shou, serie de ejercicios para dos ejecutantes que integra el arte marcial chino del tai chi chuan.] 


\section{MISTÉRIO AMOROSO*}

fêmea tão somente

negra quanto água

de cascata irreal

[* Nota do autor: Mistério amoroso é uma tradução literal do ideograma chinês que simboliza a afetuosidade, formado por dois signos que representam "mistério", na parte superior, e um signo que se traduz por "coração", na parte inferior.] (1989, in Sutra)

\section{MISTERIO AMOROSO*}

hembra tan única-

mente negra como agua

de cascada irreal

[* Nota del autor: Misterio amoroso es una traducción literal del ideograma chino que simboliza el afecto y que está formado por dos signos que representan el "misterio", en la parte superior, y uno que se traduce como "corazón", en la parte inferior.]

\section{SUTRA*}

para Reginabhen

pálpebras de alfazema

cintilantes luas sem enigma

sob o céu anúbis-tânger-cicatriz

na seda cor-de-nuvem que simula o desejo

serpenteiam formas de dançarina moura

de seios tamarindo e lábios sabor anis

o seu púbis shiva kali irrompe como rosa

citara que emudece o pensar do amante

e lhe toca o coração

no mais cálido êxtase de santos dervixes

mulher sem álgebra, sem mitologia, sem cabala

ou neurocibernética quântica 
a mais-que-perfeita expressão do verbo que resume à sua maneira schopenhauer os manuscritos de alexandria os fabulosos cálculos dos astrônomos e os acordes finais de um pianista de blues dama feita para mim e o meu desejo de outro que em tuas mãos é um leão domesticado e no entanto és apenas uma mulher deitada no lado esquerdo da cama

[* Nota do autor: Sutra, em sânscrito, significa "fio" ou "linha" e designa os textos sagrados do budismo, escritos na forma de aforismos, muitos deles ditados oralmente por um mestre a seus discipulos. No verso "céu-anúbis-tânger-cicatriz" há uma referência ao deus-chacal egípcio, ligado aos ritos fúnebres.] (1991, in Sutra)

\section{SUTRA *}

para Reginabhen

párpados de alhucema

cintilantes lunas sin enigmas

bajo el cielo anubis-tánger-cicatriz

en la seda color-de-nube que simula el deseo

serpentean formas de danzarina mora

de senos tamarindo y labios sabor anis

su pubis shiva kali irrumpe como rosa

cítara que enmudece el pensar del amante

y le llega al corazón

en el más cálido éxtasis de santos derviches

mujer sin álgebra, sin mitología, sin cábala

o neurocibernética quántica

la expresión pluscuamperfecta del verbo

que resume a su manera schopenhauer

los manuscritos de alejandría

los fabulosos cálculos de los astrónomos

y los acordes finales de un pianista de blues 
dama hecha para mí y mi deseo de otro que en tus manos resulta un león domesticado mientras eres apenas una mujer acostada en el lado izquierdo de la cama

[ Nota del autor: Sutra, en sánscrito, significa "hilo" o "línea" y se refiere a los textos sagrados del budismo, escritos en forma de aforismos, muchos de ellos dictados oralmente por un maestro a sus discípulos. En el verso "änubis-tángercicatriz" hay una referencia al dios-chacal egipcio, vinculado a los ritos fúnebres.]

\title{
ZAUBERBUCH*
}

a Jorge Luis Borges

\author{
Todos \\ os livros \\ - os Sutras, o Corão, \\ os Vedas, o Zohar - \\ são enigmas: \\ jardins verticais, \\ rios insubmissos, \\ listras de mármore possesso; \\ todas as páginas \\ - em lâminas de argila, \\ pele de carneiro, \\ folhas de papiro \\ ou rubro ouro esculpido - \\ são impossíveis, \\ viscerais, \\ areia alucinada. \\ Os livros, Borges, \\ inventam os leitores \\ e os nomes \\ de vales, savanas, estepes \\ e de amplas avenidas \\ que ignoramos;
}


vivemos

essa efêmera realidade

para lermos

suas secretas linhas,

e assim

nossos filhos e netos.

Um dia, porém, os livros

- últimos demiurgos -

desaparecerão,

como o grifo e o licorne

e ler será apenas lenda.

[* Nota do autor: Zauberbuch, em alemão, significa "livro de magia", assim como o termo francês grimoire.]. (1993, in Yumê)

\section{ZAUBERBUCH*}

a Jorge Luis Borges

Todos

los libros

- los Sutras, el Corán,

los Vedas, el Zohar -

son enigmas:

jardines verticales,

ríos insumisos,

listel de mármol poseso;

todas las páginas

- en láminas de barro,

piel de carnero,

hojas de papiro

o encarnado oro tallado -

son imposibles,

viscerales,

arena alucinada.

Los libros, Borges, 


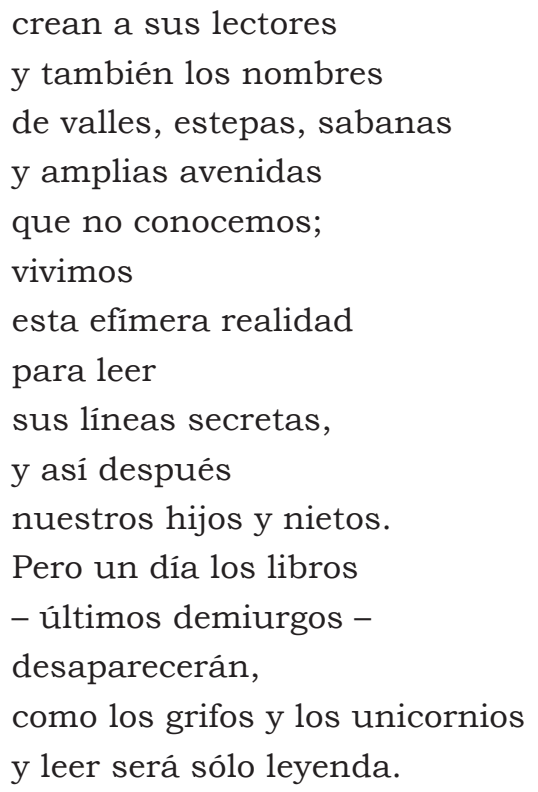

[* Nota del autor: Zauberbuch, en alemán, significa "libro de magia", igual que el término francés grimoire.]

\title{
DE PELE
}

\author{
sua \\ pele - \\ prata? não; \\ pétala; colo \\ de pássaro; \\ jade, sim, \\ luz de jade \\ nas pupilas; \\ sob a blusa \\ organdi \\ lápis-lazúli \\ teus duros \\ róseos mamilos \\ de leoparda
}


encimam

lácteos peitos

que me olham

no escuro;

teus brancos pés

de linho, desnudos

incitam à dança,

ao jogo nupcial

de pele em pele

cimentada;

em sua câmara, sob a coberta

carmesim, afinal

abrasados,

esqueço de mim,

consumido

em tua chama

vestal: labareda.

(1997, in Yumê)

\section{DE PIELSOBRE LA PIEL}

$\mathrm{su}$

piel -

plata? no;

pétalo; cuello

de pájaro;

jade, sí,

luz de jade

en las pupilas;

bajo la blusa

lapislázuli 


\author{
organdí \\ tus duras \\ róseas mamilas \\ de leoparda \\ coronan \\ lácteos pechos. \\ que me observan \\ en lo oscuro; \\ tus blancos pies \\ de lino, desnudos \\ incitan a la danza, \\ al juego nupcial \\ de piel sobre piel \\ cimentada; \\ en su alcoba, \\ bajo la cubierta \\ carmesí, finalmente \\ olvídome de mí, \\ consumido \\ en tu llama \\ vestal: llamarada.
}

\title{
SCHOPENHAUER
}

Água

de nenhum

mar, gema

de extinta mina,

não mais

que o fulgor

de vidros

(cristaleira)

e o viço 
de madeira

nova,

lua líquida.

O tempo

lacera

o verde

nos olhos

do gato,

lepra

das flores,

ácido

que corrói

toda cor

ou pele

em escuro

miasma,

peixes

do nada.

Este

é um oficio

doloroso,

uma ópera

ruidosa.

Porém,

tu foste

o tigre.

(1999, in A sombra do leopardo)

\section{SCHOPENHAUER}

Agua

de ningún

mar, gema

de extinta mina,

nada más

que el fulgor 


\author{
de vidrios \\ (cristalera) \\ y el vigor \\ de la madera \\ nueva, \\ luna líquida. \\ El tiempo \\ lacera \\ el verde \\ en los ojos \\ del gato, \\ lepra \\ de las flores, \\ ácido \\ que corroe \\ todo color \\ o piel \\ en miasma \\ oscura, \\ peces \\ de la nada. \\ Es \\ este un oficio \\ doloroso, \\ una ópera \\ ruidosa. \\ Entretanto, \\ tú fuiste \\ el tigre.
}

SÊNECA

Dor é algo

atroz (fungos

violeta). Água 
sonora, vai

de uma a outra

concha, ama-

relece (folha

de trevo) e

cai. Diz então,

em que ilha-

olho-de-chama

- Îtaca, talvez -

vesti-me de pele

desolada,

e padeci, fera

entre feras?

Por que, brutal,

me arrasto

nesta terra?

Para a glória

do Sublime?

Por meus débitos,

hora de decepar

vogais? Cala Sibila, calam Córdova

e Roma, sou todo

farelo, e se fecha

a porta do canto.

Que direi a mim, após celebrar

o rito da memória?

- Bebe o teu vinho

e aceita o universo,

eis o caminho

da iniciação.

(1999, in A sombra do leopardo) 


\section{SÉNECA}

El dolor es algo

atroz (hongos

violeta). Agua

sonora, ve

de una a otra

concha, ama-

rillea (hoja

de trébol) y

cae. Di entonces,

¿en qué isla-

ojo-de-llama

- Ítaca, tal vez -

me vestí de piel

desolada;

$y$, fiera entre fieras,

padecí?

¿Por qué, brutal,

me arrastro

en esta tierra?

¿Para mayor gloria

del Sublime?

Acaso por mis deudas,

¿hora es ya de mutilar

vocales? Calla, Sibila,

callan Córdoba

y Roma, soy todo

migaja, y se cierra

la puerta del canto.

¿Qué me diré

después de celebrar el rito

de la memoria?

- Bebe tu vino

y acepta el universo, 
he aquí el camino de la iniciación. 